\title{
Combined Aliskiren and L-arginine treatment reverses renovascular hypertension in an animal model
}

\author{
Renata V Tiradentes ${ }^{1}$, Cintia H Santuzzi ${ }^{1}$, Erick RG Claudio ${ }^{1}$, Vinicius Mengal ${ }^{1}$, Nyam F Silva ${ }^{2}$, \\ Henrique AF Neto ${ }^{2,3,4}$, Nazaré S Bissoli ${ }^{1}$, Glaucia R Abreu ${ }^{1}$ and Sonia A Gouvea ${ }^{1,5}$
}

Renovascular hypertension is characterized by increased renal sympathetic activity, angiotensin II and by endothelial dysfunction. The purpose of this study was to determine the role of renal sympathetic nerve activity (RSNA) in mediating the anti-hypertensive effects of aliskiren (ALSK) and L-arginine (L-ARG) in a rat renovascular hypertension model. Hypertension was induced by clipping the right renal artery, and the following five groups were divided: SHAM operated; 2-kidney, 1-clip (2K1C); 2K1C plus ALSK; 2K1C plus L-ARG; and 2K1C plus ALSK+ L-ARG. The systolic blood pressure (SBP) of 2K1C rats increased from $114.4 \pm 5.2$ to $204 \pm 12.7 \mathrm{~mm} \mathrm{Hg}(P<0.05)$ and was only reduced by ALSK+L-ARG treatment $(138.4 \pm 4.37 \mathrm{~mm} \mathrm{Hg})$. The $2 \mathrm{~K} 1 \mathrm{C}$ hypertension increased the baseline RSNA (SHAM: $62.4 \pm 6.39$ vs. $2 \mathrm{~K} 1 \mathrm{C}$ : $97.4 \pm 8.43 \%$ ). L-ARG or ALSK+L-ARG treatment significantly decreased baseline RSNA (2K1C L-ARG:70.7 \pm 2.39 ; $2 \mathrm{~K} 1 \mathrm{C}$ ALSK+L-ARG: $69.3 \pm 4.23 \%$ ), but ALSK treatment alone did not (2K1C ALSK: $84.2 \pm 2.5 \%$ ). Urinary water, $\mathrm{Na}^{+}, \mathrm{Cl}^{-}$and urea excretion were similar in the $2 \mathrm{~K} 1 \mathrm{C}$ L-ARG, 2K1C ALSK+L-ARG and SHAM groups. The combination of ALSK+L-ARG restored urine flow and increased the glomerular filtration rate. The nNOS expression in the non clipped kidney was significantly increased in 2K1C ALSK+L-ARG rats. In conclusion, combined ALSK+L-ARG treatment normalizes SBP and prevents renal dysfunction in 2K1C hypertensive rats. Hypertension Research (2015) 38, 471-477; doi:10.1038/hr.2015.16; published online 5 March 2015

Keywords: 2K1C hypertension; aliskiren; L-arginine; renal function; renal sympathetic nerve activity

\section{INTRODUCTION}

Hypertension is related not only to the development but also to the progression of renal disease. Several studies have analyzed the factors influencing the progression to chronic renal disease. Overactivity of the sympathetic nervous system has been implicated in the development and maintenance of essential and renovascular hypertension in humans. ${ }^{1-4}$ Studies in hypertensive animal models show an increase in basal renal sympathetic nerve activity (RSNA). ${ }^{5,6}$ The excessive sympathetic nerve activity has a pathogenic role in triggering and sustaining both hypertension and a progression to organ damage. In particular, alterations in RSNA that influence hormones affecting renal function and urinary salt and water excretion influence blood pressure in the long term, ${ }^{7}$ and inhibition of sympathetic activation has an antihypertensive effect. ${ }^{8,9}$ In addition, the positive impact of a lower RSNA was associated with a trend toward greater blood flow and improved vascular conductance in the stenotic kidney. ${ }^{4}$ However, the mechanism of sympathetic activation in hypertension is not well understood. $^{10}$ Renal nerves are known to produce renal vasoconstriction, albeit at higher levels of RSNA than are required to release renin. ${ }^{4}$
Importantly, in the two-kidney, one-clip (2K1C) model of renovascular hypertension, excitatory synaptic inputs to the rostral ventrolateral medulla and the cardiac sympathetic afferent reflex are enhanced, ${ }^{10}$ factors that may partly contribute to sympathetic activation and hypertension. ${ }^{11}$ In $2 \mathrm{~K} 1 \mathrm{C}$ renovascular hypertension, the renal artery stenosis caused by the clip reduces the perfusion of the clipped kidney, raising plasma renin activity and circulating angiotensin II (Ang II), and increasing systolic blood pressure (SBP). In addition, various functional abnormalities, including impaired endotheliumdependent vasodilation, have been reported in the contralateral, non-clipped kidney.

The renin-angiotensin-aldosterone system (RAAS) has a pivotal role in the pathogenesis of $2 \mathrm{~K} 1 \mathrm{C}$ hypertension. The renin-angiotensin blockers, such as angiotensin-converting enzyme inhibitors (ACEIs), AT1 receptor antagonists (ARBs), and, more recently, renin inhibitors 4 are one class of drugs used for treatment. Many clinical trials have demonstrated that blockade of RAAS prevents the development and progression of chronic kidney disease and its complications, such as hypertension and cardiovascular disease. Moreover, renal sympathetic denervation have recently been developed as treatments for resistant

${ }^{1}$ Department of Physiological Sciences, Health Sciences Center, Federal University of Espírito Santo, Vitória-ES, Brazil; ${ }^{2}$ Department of Morphology, Health Sciences Center, Federal University of Espírito Santo, Vitória-ES, Brazil; ${ }^{3}$ Univix Medical School, Vitória-ES, Brazil; ${ }^{4}$ Emescam Medical School, Vitória-ES, Brazil and ${ }^{5}$ Nucleus of Biotechnology, Centro de Ciências da Saúde, Federal University of Espirito Santo (UFES), Vitória-ES, Brazil

Correspondence: Professor Dr SA Gouvea, Nucleus of Biotechnology, Health Sciences Center, Federal University of Espirito Santo (UFES), Avenida Marechal Campos, 1456 - Maruípe, Vitoria-ES, CEP 29040-577, Brazil.

E-mail: gouveasa@yahoo.com.br or sagouvea@ppgcf.ufes.br

Received 5 September 2014; revised 12 January 2015; accepted 25 January 2015; published online 5 March 2015 
hypertension ${ }^{12}$ as well as inhibition of the sympathetic nervous system is an appropriate and effective treatment for renovascular hypertension. ${ }^{4}$

Aliskiren is an orally active, non-peptide, direct renin inhibitor, which acts by binding to the active site of renin. Aliskiren directly inhibits PRA, the initial and rate-limiting step in the RAAS, unlike the ACEIs and ARBs, which cause a reactive rise in PRA. ${ }^{13}$

Several clinical studies have demonstrated that aliskiren is effective in decreasing blood pressure in patients with mild-to-moderate hypertension ${ }^{14}$ and prevents and ameliorates insulin resistance, aortic endothelial dysfunction and oxidative vascular remodeling in fructosefed hypertensive rats. ${ }^{15}$

A previous study has reported that oral L-ARG reduced SBP and acted on the kidney, possibly inducing changes in renal hemodynamics or tubular transport due to an increase in nitric oxide (NO) formation. ${ }^{16}$

Since in renovascular hypertension there is an excessive activation of the RAAS and a labeled endothelial dysfunction, the present study aims to examine the effects of ALSK and L-ARG, alone or in combination, on blood pressure control, renal sympathetic activity and renal function, and evaluates the reversal and/or prevention of cardiac and renal alterations induced by renovascular hypertension. We also aimed to investigate factors that could be related to a better antihypertensive response.

\section{METHODS}

\section{Animals and treatment}

Male Wistar rats (150-170 g) were used for these studies. The care and use of laboratory animals were in accordance with $\mathrm{NIH}$ guidelines, and all experiments were conducted in compliance with the guidelines for biomedical research as stated by the Brazilian Societies of Experimental Biology and were approved by the Institutional Ethics Committee of the Federal University of Espírito Santo (CEUA-UFES 004/2010). All rats had free access to water and were fed rat chow ad libitum. Rats were divided into five groups: SHAM (normotensive control, vehicle-saline, by gavage, $0.3 \mathrm{ml}$ ); two-kidney one-clip (2K1C; hypertension control, vehicle-saline, by gavage, $0.3 \mathrm{ml}$ ); two-kidney one-clip treated with aliskiren (2K1C ALSK; dose: $50 \mathrm{mg} \mathrm{kg}^{-1}$ by gavage, $0.3 \mathrm{ml} \mathrm{day}^{-1}$ ); two-kidney one-clip treated with $\mathrm{L}$-arginine (2K1C L-ARG; dose: $10 \mathrm{mg} \mathrm{kg}^{-1}$ by gavage, $0.3 \mathrm{ml} \mathrm{day}^{-1}$ ) and two-kidney one-clip treated with aliskiren and L-arginine. (2K1C ALSK+L-ARG; aliskiren dose: $50 \mathrm{mg} \mathrm{kg}^{-1}$ and L-arginine dose: $10 \mathrm{mg} \mathrm{kg}^{-1}$ by gavage, $0.3 \mathrm{ml} \mathrm{day}^{-1}$ ).

\section{Surgical procedures and experimental design}

Renovascular hypertension was induced by the Goldblatt 2K1C method as described in our previous reports. ${ }^{16,17}$ Under intraperitoneal anesthesia with ketamine $\left(80 \mathrm{mg} \mathrm{kg}^{-1}\right)$ and xylazine $\left(5 \mathrm{mg} \mathrm{kg}^{-1}\right)$, a 0.20 - $\mathrm{mm}$ internal diameter silver clip was placed through a flank incision around the right renal artery to induce renovascular hypertension (2K1C). SHAM-operated rats underwent a similar procedure with manipulation of the right renal artery but without permanent application of the clip. The criterion for hypertension in the present study was an SBP $>160 \mathrm{~mm} \mathrm{Hg}$. Only rats with SBP $>160 \mathrm{~mm} \mathrm{Hg} 7$ days after surgery were used in the experiments.

The treatments were started 7 days after surgery and lasted for 3 weeks. The animals were kept in metabolic cages for the last $24 \mathrm{~h}$ of treatment to collect urine to monitor electrolyte balance, urinary flow and glomerular filtration rate (GFR). Urine $\mathrm{Na}^{+}, \mathrm{K}^{+}, \mathrm{Cl}^{-}$and urea concentrations were measured using a flame photometry. The GFR was determined by creatinine clearance (calculated as $\left(U_{\mathrm{c} \times} V\right) / P_{\mathrm{cr}}$, where $U_{\mathrm{cr}}$ is urinary concentration of creatinine $\left(\mathrm{mg} \mathrm{ml}^{-1}\right), V$ is urinary flow $\left(\mathrm{ml} \mathrm{min}^{-1}\right)$ and $P_{\mathrm{cr}}$ is plasma concentration of creatinine $\left(\mathrm{mg} \mathrm{ml}^{-1}\right) \cdot{ }^{18}$

At the end of each experiment, the animals were decapitated, and a blood sample was taken to measure plasma creatinine. The kidneys and left ventricle were removed and decapsulated, and the left ventricle and kidney weight/body weight ratios were determined.

\section{Measurement of SBP}

The SBP of the tail artery was measured before production of hypertension and 7 and 28 days after surgery in conscious rats by a non-invasive computerized tail-cuff system (IITC Life Science Inc., Victory Blvd Woodland Hills, CA, USA). The rats were trained by measuring their SBP daily for at least 5 days before $2 \mathrm{~K} 1 \mathrm{C}$ or SHAM operation. To validate the values obtained by plethysmography, at the end of treatment the rats were catheterized for direct measurement of SBP.

\section{Renal sympathetic nerve activity}

Anesthesia was induced with 3\% halothane in a chamber and maintained with urethane $\left(1.2 \mathrm{~g} \mathrm{~kg}^{-1}\right.$, i.v.). Supplementary doses of urethane were administered as required. The femoral artery was cannulated to measure blood pressure with a pressure transducer (Viggo-Spectramed, P23XL, Oxnard, CA, USA), and the heart rate was derived electronically from the blood pressure signal using a rate meter (Biotach, Gould 13-64616-66, Valley View, OH, USA). The left femoral vein was cannulated for drug administration. Rectal temperature was maintained between 37 and $37.5^{\circ} \mathrm{C}$ with a thermostatically controlled heating blanket (Harvard, Harvard Apparatus, Holliston, MA, USA).

The left kidney was exposed via a retroperitoneal approach, and a renal nerve bundle was dissected carefully and freed from the surrounding tissue under microscope magnification $(\times 32)$. The nerve was placed on a silver bipolar electrode and covered with mineral oil. The nerve activity was displayed on an oscilloscope (Tektronix 2205, Beaverton, OR, USA) and monitored by audio amplification (Neurolog NL120, Welwyn Garden City, Hertfordshire, UK). The signal was amplified (Neurolog NL104, Digitimer) and filtered (Neurolog NL126, Digitimer). All cardiovascular and nerve activity data were digitalized (Acknowledge for Windows, Biopac MP 100, Goleta, CA, USA) and stored on a PC hard disk for later processing.

To evaluate the sympathetic responsiveness to vasoactive drugs, phenylephrine (PE, $8 \mu \mathrm{g} \mathrm{kg}^{-1}$, i.v.) was injected in each animal to obtain a typical reflex tachycardia and sympatho-inhibition. Similarly, sodium nitroprusside (SNP, $25 \mathrm{\mu} \mathrm{kg}^{-1}$, i.v.) gave a reflex bradycardia and sympatho-excitation. After giving $\mathrm{PE}$ or SNP, the renal nerve activity was recorded as the difference $(\Delta)$ from each basal value. The baseline RSNA was calculated as a percentage of maximal RSNA (the RSNA before SNP divided by the maximal RSNA after SNP) $\times 100 \%{ }^{19}$

\section{Western blot analyses}

The clipped and non-clipped kidneys were homogenized in lysis buffer containing (in mmoll ${ }^{-1}$ ) $150 \mathrm{NaCl}, 50$ Tris- $\mathrm{HCl}, 5$ EDTA.2Na, $1 \mathrm{MgCl}_{2}$ plus protease inhibitor (Sigma Fast; Sigma-Aldrich, St Louis, MO, USA). The protein concentration was determined by the Lowry method, ${ }^{20}$ using bovine serum albumin (BSA) as a standard. Equal amounts of protein $(50 \mu \mathrm{g})$ were separated by $10 \%$ sodium dodecyl sulfate-PAGE (SDS-PAGE). Proteins were transferred to polyvinylidene difluoride membranes that were incubated with mouse monoclonal antibodies to endothelial nitric oxide synthase (eNOS; 1:1500; BD, New Jersey, NJ, USA), inducible nitric oxide synthase (iNOS; 1:1500; BD, New Jersey, NJ, USA) and neuronal nitric oxide synthase (nNOS; 1:250; Santa Cruz Biotechnology, CA, USA). After washing, the membranes were incubated with an alkaline phosphatase conjugated anti-mouse IgG (1:3000, Abcam, Cambridge, MA, USA) or anti-rabbit (1:7000; Santa Cruz Biotechnology, Santa Cruz, CA, USA). The bands were visualized using an NBT/BCIP system (Invitrogen Corporation, Carlsbad, CA, USA) and quantified using the ImageJ software (National Institute of Health, NIH). The same membranes were used to determine $\beta$-actin expression using a mouse monoclonal antibody to $\beta$-actin (1:5000; Sigma Chemical, St Louis, CO, USA). The results were calculated as the ratio of the density of specific bands to the corresponding $\beta$-actin.

\section{Drugs and reagents}

The following substances were used: halothane (Cristalia, Itapira, SP, Brazil); Rasilez (Aliskiren; Novartis, Italy); phenylephrine hydrochloride, sodium nitroprusside, urethane and L-Arginine monohydrochloride were purchased from Sigma-Aldrich (St Louis, CO, USA). Salts and reagents used were of analytical grade from Sigma-Aldrich and Merck (Darmstadt, Germany). The drugs were freshly prepared and injected using saline $0.9 \%$ as a vehicle. 
Table 1 Effects of aliskiren (ALSK), L-arginine (L-ARG) or aliskiren plus L-arginine (ALSK+L-ARG) treatment on the systolic blood pressure $(\mathrm{SBP}, \mathrm{mm} \mathrm{Hg})$, kidney and left ventricle weight $\left(\mathrm{mg} \mathrm{g}^{-1}\right)$ in $2 \mathrm{~K} 1 \mathrm{C}$ rats

\begin{tabular}{|c|c|c|c|c|c|}
\hline & SHAM & $2 K 1 C$ & $2 K 1 C A L S K$ & $2 K 1 C L-A R G$ & $2 K 1 C A L S K+L-A R G$ \\
\hline SBP Day 7 & $120.2 \pm 3.64$ & $204.4 \pm 12.7^{*}$ & $217.8 \pm 10.2^{*}$ & $197.5 \pm 8.92^{*}$ & $197.14 \pm 6.1^{*}$ \\
\hline Direct SBP & $108.3 \pm 5.21$ & $198.3 \pm 13.39 *$ & $198.7 \pm 9.09^{*}$ & $167.9 \pm 13.5^{*}$ & $140.8 \pm 9.74^{\#,+}$ \\
\hline Kidney weight (non clipped) & $4.1 \pm 0.17$ & $6.1 \pm 0.5^{*}$ & $6.1 \pm 0.82^{*}$ & $4.3 \pm 0.33$ & $4.0 \pm 0.36^{\#,+}$ \\
\hline Kidney weight (clipped) & $4.1 \pm 0.17$ & $2.3 \pm 0.31^{* *}$ & $2.1 \pm 0.35^{* *}$ & $3.4 \pm 0.21$ & $3.1 \pm 0.28$ \\
\hline
\end{tabular}

Abbreviation: 2K1C, two-kidney one-clipped.

Data are shown as mean \pm s.e.m. ( $n=7-9$ per group). ${ }^{* *} P<0.01$ and ${ }^{*} P<0.05$ vs. the SHAM group; ${ }^{\#} P<0.01$ and ${ }^{\#} P<0.05$ vs. the $2 \mathrm{~K} 1 \mathrm{C}$ group; ${ }^{++} P<0.01$ and ${ }^{+} P<0.05$ vs. the $2 \mathrm{~K} 1 \mathrm{C}$ ALSK group.

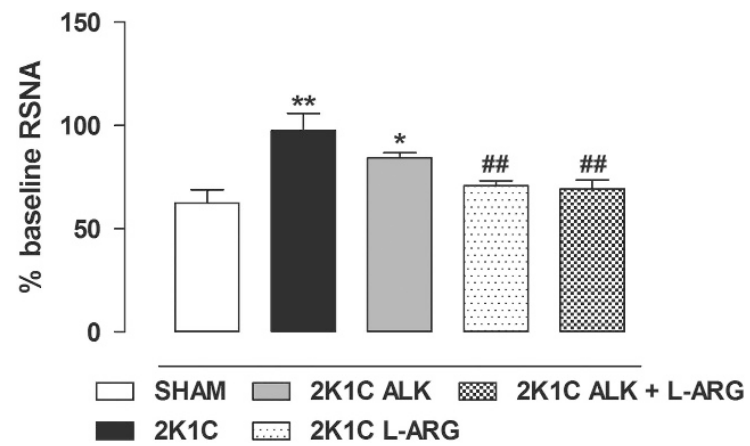

Figure 1 Effects of aliskiren (ALSK), L-arginine (L-ARG) or aliskiren plus $\mathrm{L}$-arginine (ALSK+L-ARG) treatment on the baseline renal sympathetic nerve activity (RSNA) in $2 \mathrm{~K} 1 \mathrm{C}$ rats. ${ }^{* *} P<0.01$ and ${ }^{*} P<0.05$ compared with SHAM; $\# \#<0.01$ compared with $2 \mathrm{~K} 1 \mathrm{C}$.

\section{Statistical analysis}

The changes in renal function, renal nerve activity and protein expression were analyzed by one-way analysis of variance (ANOVA) for repeated measures followed by Tukey's test for post hoc comparison of the means. For protein expression, the data were expressed as the ratio between the densities on the immunoblot corresponding to the protein of interest and $\beta$-actin. For all analyses, differences were considered significant when $P<0.05$.

\section{RESULTS}

Effects of aliskiren and L-arginine treatments on development of 2K1C hypertension

SBP values were similar in all groups of rats at the beginning of the study (Table 1) but were increased 1 week after clip placement in all operated compared with SHAM-operated rats. After 21 days of treatment, the SBP of ALSK+L-ARG group decreased by $29.8 \%$ as compared to untreated $2 \mathrm{~K} 1 \mathrm{C}$ rats. The ALSK plus L-ARG group presented similar SBP values to the SHAM group. ALSK treatment for 21 days induced a decrease of $7.07 \%(15.4 \mathrm{~mm} \mathrm{Hg})$ in SBP as compared to $2 \mathrm{~K} 1 \mathrm{C}$ rats. A reduction of $11.09 \%(21.9 \mathrm{~mm} \mathrm{Hg})$ in SBP was observed in L-ARG group as compared to $2 \mathrm{~K} 1 \mathrm{C}$ rats. Direct systolic pressure in conscious rats was measured and showed statistically similar values to those obtained by plethysmography at the end of treatment (Table 1).

The effects of aliskiren and L-arginine treatments on left ventricle and kidney weight

Kidney/body weight ratios of the rats are shown in Table 1. ALSK treatment did not reverse the atrophy of the clipped kidney compared with the 2K1C group, and in addition, the non-clipped kidneys of 2K1C and 2K1C ALSK animals were heavier than those of the other groups. Only the $2 \mathrm{~K} 1 \mathrm{C}$ ALSK+L-ARG rats showed similar values to the SHAM group for the weights of the clipped and non-clipped kidney. Moreover, the renovascular hypertension promoted hypertrophy of the left ventricle in all clipped groups other than those treated with $\mathrm{L}-\mathrm{ARG}$ or ALSK+L-ARG, whose levels did not differ from the SHAM group (Table 1).

Effects of aliskiren and L-arginine treatments on renal nerve activity and renal function

The 2K1C-induced hypertension increased the baseline RSNA (SHAM: $62.4 \pm 6.39$ vs. $2 \mathrm{~K} 1 \mathrm{C}$ : $97.4 \pm 8.43 \%$ ). ALSK treatment did not decrease the baseline RSNA (2K1C ALSK: $84.2 \pm 2.5 \%$ ); however, treatment with L-ARG or ALSK plus L-ARG did so significantly (2K1C L-ARG:70.7 $\pm 2.39 ; \quad 2 \mathrm{~K} 1 \mathrm{C} \quad$ ALSK+L-ARG: $69.3 \pm 4.23 \%$ ) (Figure 1). Furthermore, the sympathetic responses to injection of PE and SNP were decreased in the $2 \mathrm{~K} 1 \mathrm{C}, 2 \mathrm{~K} 1 \mathrm{C}$ ALSK and 2K1C L-ARG groups compared with the SHAM rats, and only the 2K1C ALSK+L-ARG group was restored to values similar to the SHAM group (\% $\Delta$ PE in SHAM: $-57.1 \pm 5.40 ; 2 \mathrm{~K} 1 \mathrm{C}:-24.7 \pm 3.60$; 2K1C ALSK: $-30.3 \pm 2.48$; 2K1C L-ARG: $-33.9 \pm 3.92$; $2 \mathrm{~K} 1 \mathrm{C}$ ALSK +L-ARG: $-55.4 \pm 6.36$ and $\% \Delta$ SNP in SHAM: $78.1 \pm 13.21$; $2 \mathrm{~K} 1 \mathrm{C}$ : $12.6 \pm 3.37$; $2 \mathrm{~K} 1 \mathrm{C}$ ALSK: $21.4 \pm 3.67$; 2K1C L-ARG: $38.4 \pm 3.33$; $2 \mathrm{~K} 1 \mathrm{C}$ ALSK+L-ARG: $49.2 \pm 8.79$ ) (Figure 2).

To evaluate renal function in the renovascular hypertensive rats, the plasma urea and the urinary excretion of water, $\mathrm{Na}^{+}, \mathrm{K}^{+}, \mathrm{Cl}^{-}$and urea were measured (Table 2). The excretion of water, $\mathrm{Na}^{+}, \mathrm{Cl}^{-}$and urea was decreased in both $2 \mathrm{~K} 1 \mathrm{C}$ and $2 \mathrm{~K} 1 \mathrm{C}$ ALSK groups compared with SHAM rats, while $2 \mathrm{~K} 1 \mathrm{C}$ L-ARG and $2 \mathrm{~K} 1 \mathrm{C}$ ALSK+L-ARG groups showed similar values to the SHAM group. In contrast, the $\mathrm{K}^{+}$ excretion was increased only in $2 \mathrm{~K} 1 \mathrm{C}$ rats and the plasma urea was increased in $2 \mathrm{~K} 1 \mathrm{C}$ and $2 \mathrm{~K} 1 \mathrm{C}$ ALSK rats compared with SHAM rats (Table 2).

Urinary flow was significantly reduced in both $2 \mathrm{~K} 1 \mathrm{C}$ and $2 \mathrm{~K} 1 \mathrm{C}$ ALSK groups compared with SHAM rats, and the GFR was increased in $2 \mathrm{~K} 1 \mathrm{C}$ L-ARG and $2 \mathrm{~K} 1 \mathrm{C}$ ALSK+L-ARG animals compared with $2 \mathrm{~K} 1 \mathrm{C}$ rats (Table 2).

Expression of nNOS, iNOS and eNOS in clipped and non-clipped kidney

The nNOS expression in the clipped kidney was significantly increased in $2 \mathrm{~K} 1 \mathrm{C}$ L-ARG rats compared with SHAM and $2 \mathrm{~K} 1 \mathrm{C}$ rats. In the non-clipped kidney, nNOS expression was significantly decreased in 
$2 \mathrm{~K} 1 \mathrm{C}$ rats compared with the SHAM group and increased in $2 \mathrm{~K} 1 \mathrm{C}$ $\mathrm{L}-\mathrm{ARG}$ and 2K1C ALSK+L-ARG compared with 2K1C rats (Figure 3).

The iNOS expression in the clipped kidney was increased in $2 \mathrm{~K} 1 \mathrm{C}$ animals compared with SHAM rats. Similarly, in the non-clipped kidney, iNOS expression was increased in the $2 \mathrm{~K} 1 \mathrm{C}$ and $2 \mathrm{~K} 1 \mathrm{C}$ L-ARG rats compared with all other groups (Figure 4).

The eNOS expression in the clipped kidney was decreased in $2 \mathrm{~K} 1 \mathrm{C}$ rats compared with the SHAM group and was increased in $2 \mathrm{~K} 1 \mathrm{C}$ L-ARG rats compared with $2 \mathrm{~K} 1 \mathrm{C}, 2 \mathrm{~K} 1 \mathrm{C}$ ALSK and $2 \mathrm{~K} 1 \mathrm{C}$ ALSK+LARG groups. However, there were no significant differences in eNOS expression in the non-clipped kidneys (Figure 5).

\section{DISCUSSION}

Our results demonstrates that combined Aliskiren and L-arginine treatment reverses renovascular hypertension in an animal model. This study provides three important new findings relevant to the
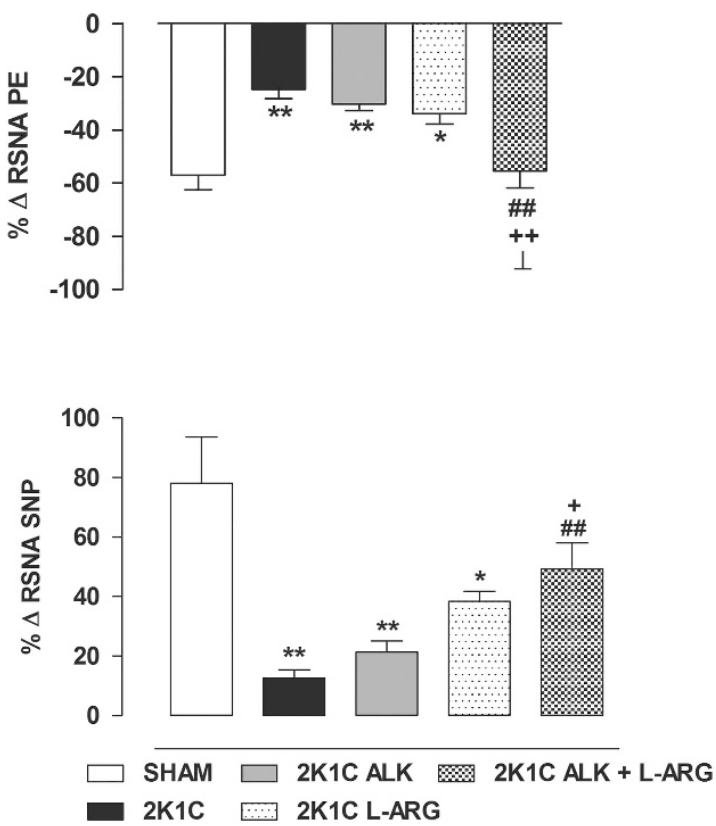

Figure 2 Effects of aliskiren (ALSK), L-arginine (L-ARG) or aliskiren plus $\mathrm{L}$-arginine (ALSK+L-ARG) treatment on the baseline renal sympathetic nerve activity (RSNA) in $2 \mathrm{~K} 1 \mathrm{C}$ rats after phenylephrine (PE) and sodium nitroprusside (SNP) injections. ${ }^{*} P<0.01$ and ${ }^{*} P<0.05$ compared with SHAM; $\quad \# \#<0.01$ compared with $2 \mathrm{~K} 1 \mathrm{C}$; ${ }^{++} P<0.01$ and ${ }^{+} P<0.05$ compared with $2 \mathrm{~K} 1 \mathrm{C} \mathrm{ALSK} ;{ }^{\dagger} P<0.01$ compared with $2 \mathrm{~K} 1 \mathrm{C}$ L-ARG. potential use of ALSK plus L-ARG for the treatment of renovascular hypertension. The first finding was that blood pressure normalized after 21 days of treatment. The second finding was a reduction in RSNA and enhanced sympathetic responsiveness. The third finding was restoration of renal function as assessed by the urinary excretion of water, $\mathrm{Na}^{+}, \mathrm{K}^{+}, \mathrm{Cl}^{-}$and urea, and the urinary flow and GFR.

During the early phase of $2 \mathrm{~K} 1 \mathrm{C}$ hypertension, while SBP is increasing (up to 4 weeks after clipping), the increase has been attributed to a combination of elevated Ang II, altered plasma volume, changes in renal function and increased renal nerve activity. $3,4,7,16$ Blocking the RAAS by inhibiting renin with ALSK could therefore contribute to reducing renovascular hypertension in the rat model we studied. However, we found that ALSK monotherapy did not reduce SBP, while studies in humans have demonstrated a reduction of blood pressure. ${ }^{14}$ Nevertheless we cannot refute that a higher dose of ALSK monotherapy in our experimental protocol could evoke more robust effects. The same dose of aliskiren used in this study was previously used by Martins-Oliveira et al., ${ }^{21}$ and the authors also observed that 3 weeks of treatment with aliskiren and losartan was unable to reduce blood pressure. Reduction of blood pressure could only be observed after 4 weeks of treatment. The hypotensive effect of ALSK is potentiated when used in combination with diuretics or blockers of the RAAS. ${ }^{22}$ Moreover, monotherapy with L-ARG was able to reduce but not normalize SBP, as observed in this study and in previous studies from our laboratory. ${ }^{16}$ However, our most important finding is that the combination of these therapies significantly reduced the blood pressure of the hypertensive rats. It has been postulated that the major factors in the development of $2 \mathrm{~K} 1 \mathrm{C}$ hypertension are an increase in Ang II and endothelial dysfunction. ${ }^{23}$ Blocking the renin associated with administration of exogenous L-ARG could, via production of $\mathrm{NO}$, restore endothelial function and reduce blood pressure in experimental hypertension.

Our results with regard to the decrease of RSNA also suggest that the antihypertensive effect of ALSK and L-ARG could be partially due to reduced sympathetic activity. The paraventricular nucleus is an important regulator of sympathetic outflow via projections to the intermediolateral column of the spinal cord and the rostral ventrolateral medulla. Within the paraventricular nucleus, Ang II enhances the sympathetic activity and blood pressure of $2 \mathrm{~K} 1 \mathrm{C}$ rats, whereas $\mathrm{NO}$ has a sympathoinhibitory effect in the paraventricular nucleus and its reduction in rostral ventrolateral medulla causes sympathoexcitation in hypertension. ${ }^{24}$ Overexpression of nNOS in the paraventricular nucleus may be responsible for increased suppression of sympathetic outflow. $^{25,26}$ Thus, the ALSK inhibition of renin would reduce the

Table 2 Effects of aliskiren (ALSK), L-arginine (L-ARG) or aliskiren plus L-arginine (ALSK+L-ARG) treatment on the urinary excretion, urinary flow and glomerular filtration rate (GFR) in $2 \mathrm{~K} 1 \mathrm{C}$ rats

\begin{tabular}{|c|c|c|c|c|c|}
\hline & SHAM & $2 K 1 C$ & $2 K 1 C$ ALSK & $2 K 1 C L-A R G$ & $2 K 1 C$ ALSK+L-ARG \\
\hline Excretion volume $\left(\mathrm{ml} \mathrm{day}^{-1}\right)$ & $20.0 \pm 2.04$ & $11.1 \pm 0.57^{*}$ & $9.1 \pm 1.04^{* *}$ & $16.7 \pm 3.24$ & $14.0 \pm 2.23$ \\
\hline Urinary flow ( $\left.\mathrm{ml} \mathrm{min}^{-1}\right)$ & $0.014 \pm 0.0004$ & $0.007 \pm 0.0002^{* *}$ & $0.006 \pm 0.0005^{* *}$ & $0.012 \pm 0.002^{\#,++}$ & $0.011 \pm 0.0002^{\#,+}$ \\
\hline GFR $\left(\mathrm{ml} \mathrm{min}^{-1}\right)$ & $1.06 \pm 0.19$ & $0.285 \pm 0.03^{* *}$ & $0.37 \pm 0.04^{* *}$ & $1.3 \pm 0.13^{\# \#,++}$ & $1.09 \pm 0.16^{\# \#,++}$ \\
\hline $\mathrm{Na}^{+}$excretion (mEq day ${ }^{-1}$ ) & $148.0 \pm 14.1$ & $48.2 \pm 7.9 * *$ & $48.5 \pm 9.2^{* *}$ & $120.6 \pm 8.2^{\# \#,++}$ & $129.8 \pm 4.5^{\# \#,++}$ \\
\hline $\mathrm{K}^{+}$excretion (mEq day ${ }^{-1}$ ) & $59.9 \pm 6.25$ & $127.4 \pm 12.4^{*}$ & $54.8 \pm 6.33^{\# \#}$ & $78.3 \pm 12.2^{\#}$ & $49.4 \pm 2.57 \# \#$ \\
\hline $\mathrm{Cl}^{-}$excretion (mEq day ${ }^{-1}$ ) & $273.8 \pm 27.01$ & $123.6 \pm 21.81 *$ & $133.7 \pm 29.50^{*}$ & $241.8 \pm 12.81^{\#,+}$ & $279.8 \pm 37.57^{\#,+}$ \\
\hline Urinary urea $\left(\mathrm{mg} \mathrm{ml}^{-1}\right)$ & $3408 \pm 538.3$ & $1288 \pm 282.1^{* *}$ & $1287 \pm 81.1^{* *}$ & $4399 \pm 314.3^{\# \#,++}$ & $4234 \pm 425.4^{\# \#,++}$ \\
\hline Plasmatic urea (mg ml-1) & $52.0 \pm 4.07$ & $84.8 \pm 4.23^{*}$ & $80.8 \pm 10.58^{*}$ & $50.0 \pm 6.57^{\#,+}$ & $55.6 \pm 4.72^{\#}$ \\
\hline
\end{tabular}

Abbreviation: 2K1C, two-kidney one-clipped.

Data are shown as mean \pm s.e.m. ( $n=7-9$ per group). ${ }^{*} P<0.01$ and ${ }^{*} P<0.05$ vs. the Sham group; ${ }^{*} P<0.01$ and ${ }^{\#} P<0.05$ vs. the $2 \mathrm{~K} 1 \mathrm{C}$ group; ${ }^{++} P<0.01$ and ${ }^{+} P<0.05$ vs. the $2 \mathrm{~K} 1 \mathrm{C}$ ALSK group. 
a

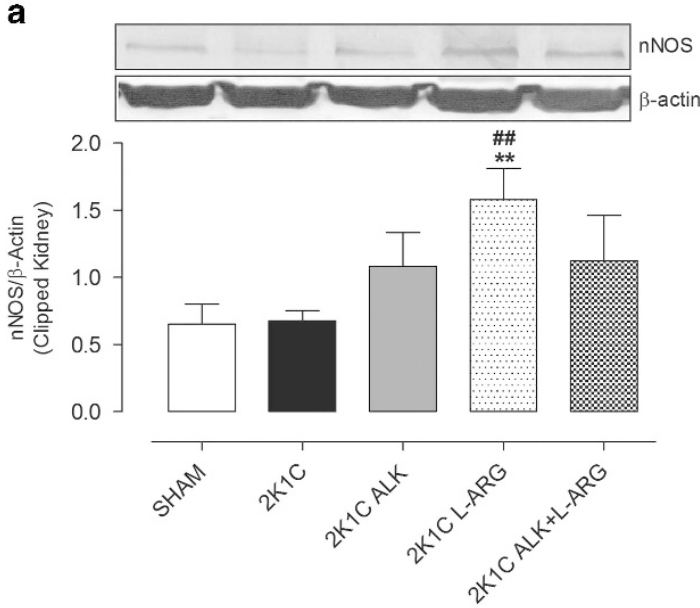

b

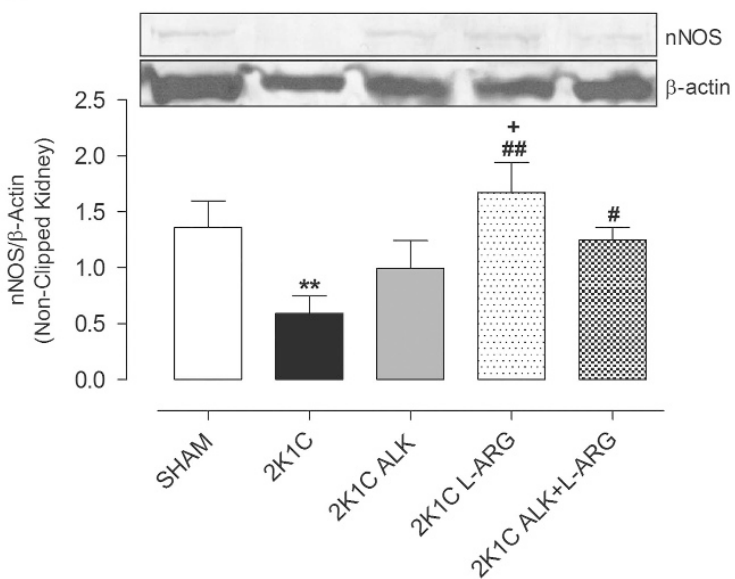

Figure 3 Protein expression of neuronal nitric oxide synthase in the clipped (panel a) and non-clipped (panel b) kidneys. Effects of aliskiren (ALSK), L-arginine $(L-A R G)$ or aliskiren plus $L$-arginine (ALSK+L-ARG) treatment on the densitometric analyses of western blots for neuronal nitric oxide synthase

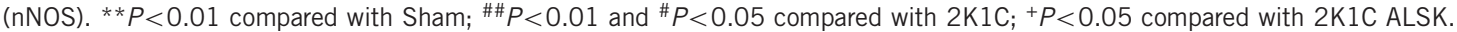

a

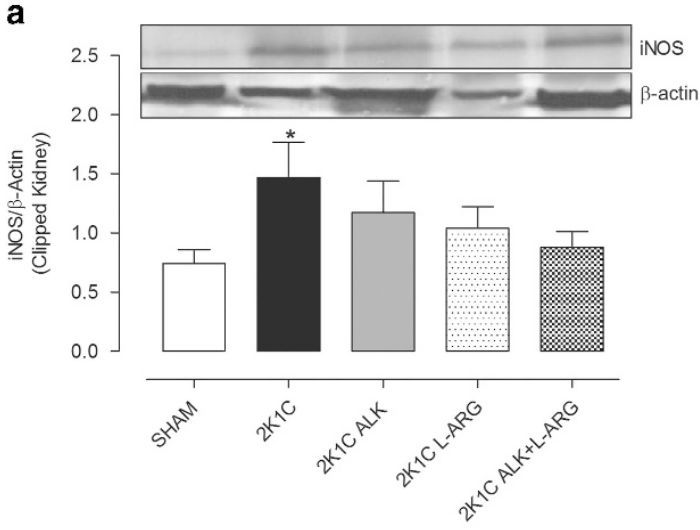

b

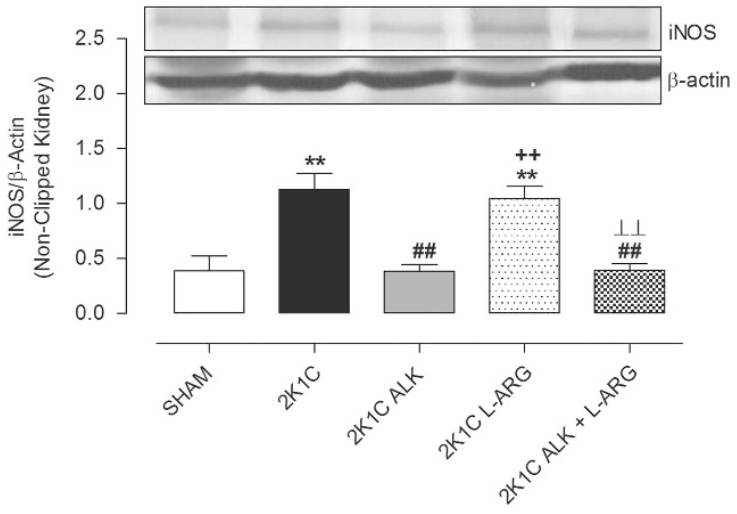

Figure 4 Protein expression of inducible nitric oxide synthase in the clipped (panel a) and non-clipped (panel b) kidneys. Effects of aliskiren (ALSK), L-arginine ( $L-A R G)$ or aliskiren plus $L$-arginine (ALSK+L-ARG) treatment on the densitometric analyses of western blots for inducible nitric oxide synthase (iNOS). ${ }^{* *} P<0.01$ and ${ }^{*} P<0.05$ compared with Sham; ${ }^{\# \# P}<0.01$ compared with $2 \mathrm{~K} 1 \mathrm{C} ;{ }^{++} P<0.01$ compared with $2 \mathrm{~K} 1 \mathrm{C}$ ALSK; ${ }^{\dagger \dagger} P<0.01$ compared with 2K1C L-ARG.

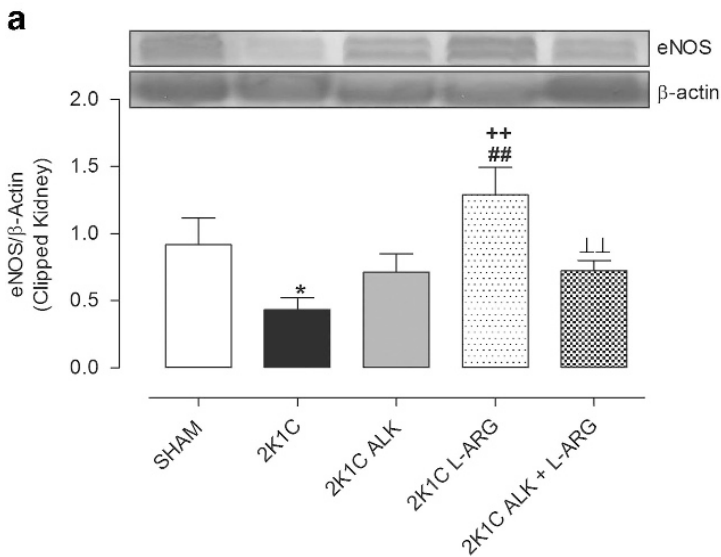

b

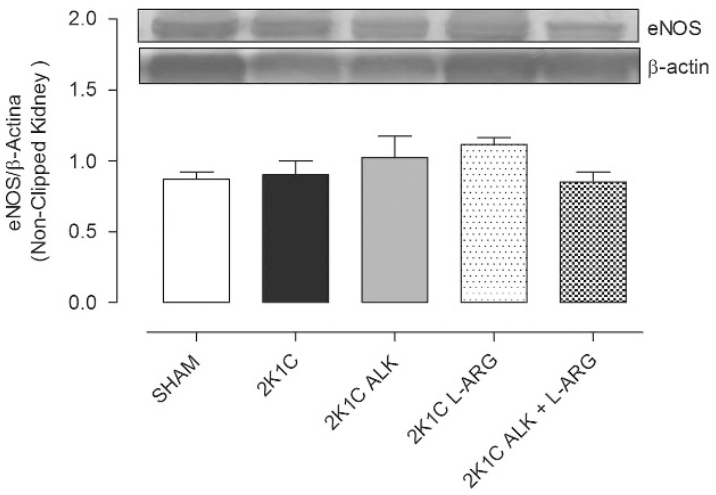

Figure 5 Protein expression of endothelial nitric oxide synthase in the clipped (panel a) and non-clipped (panel b) kidneys. Effects of aliskiren (ALSK), Larginine (L-ARG) or aliskiren plus L-arginine (ALSK+L-ARG) treatment on the densitometric analyses of western blots for endothelial nitric oxide synthase (eNOS). ${ }^{* *} P<0.01$ and ${ }^{*} P<0.05$ compared with Sham; ${ }^{\# \#} P<0.01$ compared with $2 \mathrm{~K} 1 \mathrm{C} ;{ }^{++} P<0.01$ compared with $2 \mathrm{~K} 1 \mathrm{C}$ ALSK; ${ }^{\dagger \dagger} P<0.01$ compared with 2K1C L-ARG. 
levels of Ang II and L-ARG, increasing the bioavailability of NO, as shown by reduced RSNA.

The 2K1C group showed a significant reduction in urinary flow and GFR, which can be explained by the vasoconstriction caused by Ang II in glomerular capillaries affecting renal blood flow and GFR. ALSK treatment was not able to restore these parameters. This result agrees with studies demonstrating that RAAS inhibitors can cause renal failure in situations where there is an impairment of renal blood flow, as in renovascular hypertension. ${ }^{4}$ In contrast, $\mathrm{NO}$ modulates the $2 \mathrm{~K} 1 \mathrm{C}$ phases of hypertension because its vasodilatory effect can counteract the vasoconstriction of Ang II, maintaining perfusion of the kidneys. ${ }^{27}$ This is in agreement with our results: the animals treated with L-ARG, either alone or with ALSK, showed improvement in urinary flow and GFR.

Our results showed that the $2 \mathrm{~K} 1 \mathrm{C}$ group had impaired urinary water, $\mathrm{Na}^{+}, \mathrm{Cl}^{-}$and urea excretion after 28 days' hypertension. Moreover, in this group, the $\mathrm{K}^{+}$excretion and the plasma urea were increased while urinary flow was reduced. This result illustrates the injurious effects of hypertension on renal function. Several studies have shown that these injuries are related to Ang II and, after treatment with losartan, basal renal hemodynamics (corrected for kidney weight) were similar in both non-clipped and clipped kidneys of chronic-phase $2 \mathrm{~K} 1 \mathrm{C}$-hypertensive rats, ${ }^{23}$ and in the renal medullas of both kidneys of $2 \mathrm{~K} 1 \mathrm{C}$ rats, ACE mRNA levels and activity are increased and most of the renin present is active. ${ }^{28}$ Treatment with ALSK alone was not able to improve these parameters, but, when combined with L-ARG, their values did not differ from the SHAM group. Improvement of these parameters was observed in the group treated with L-ARG alone, indicating that NO can modulate renal vasoconstriction and renal dysfunction, in addition to the RAAS. In previous studies, we observed that treatment with oral L-ARG can increase sodium and water excretion ${ }^{16}$ because $\mathrm{NO}$ contributes significant vasodilator tone, buffering the hypertension and maintaining perfusion of both kidneys. ${ }^{23}$

Renovascular hypertension promoted left ventricular hypertrophy in the $2 \mathrm{~K} 1 \mathrm{C}$ group, which may be explained by the increase of Ang II, which in turn exerted an inotropic effect and promoted the proliferation and hypertrophy of cardiac fibroblasts, leading to myocyte hypertrophy. ${ }^{29}$ ALSK treatment did not reduce cardiac hypertrophy. Other studies suggest an explanation: that direct blocking of renin reduces the ability to degrade angiotensinogen and produce Ang I, but not to inhibit the pro-fibrosis signal induced by the renin/pro-renin receptor. ${ }^{21,30}$ However, the groups treated with L-ARG did not show left ventricular hypertrophy, which suggests that the progression of cardiac damage caused by renovascular hypertension was prevented.

Likewise, the $2 \mathrm{~K} 1 \mathrm{C}$ and $2 \mathrm{~K} 1 \mathrm{C}$ ALSK rats showed atrophy of the clipped kidney and hypertrophy of the non-clipped kidney, and only the ALSK+L-ARG combination reduced the weight of non-clipped kidney. It is known that Ang II causes vasoconstriction leading to glomerular hypertrophy with increased connective tissue and to extracellular matrix deposition. ${ }^{31}$ In contrast, NO prevents glomerular hypertrophy because the plasma concentrations of ADMA (an endogenous inhibitor NO synthesis) increase markedly in patients with hypertension and are responsible for inducing vascular and glomerular fibrosis. ${ }^{32}$

Three NOS isoforms are expressed in the kidney, of which the eNOS is important for the maintenance of GFR, regional vascular tone and renal blood flow, so it has an important role in the pathophysiology of renovascular hypertension. ${ }^{33,34}$ We found a decrease in eNOS expression only in the clipped kidney. Helle et al. ${ }^{27}$ also demonstrated that the expression of eNOS in pre-glomerular resistance vessels (afferent arteriole) was reduced only in the clipped kidney. This can reduce the NO release and explain the difference between the clipped and non-clipped kidney because there is a connection between shear stress and eNOS synthesis, and, in the clipped kidney, shear stress is reduced, thereby reducing the incentive for the eNOS synthesis, limiting the release of $\mathrm{NO}$ and promoting a reduction in urinary flow. ${ }^{27}$

iNOS is expressed in the kidney under pathological conditions, such as renovascular hypertension, in tubules and in the glomerular mesangium. ${ }^{33}$ The nuclear factor kappa- $\mathrm{B}$ is activated by reactive oxygen species to induce the expression of the gene for iNOS. ${ }^{35}$ This fact confirms our finding of increased iNOS expression in $2 \mathrm{~K} 1 \mathrm{C}$ rats. Studies indicate that iNOS has an important role in the protection of the ischemic kidney, which can be explained by the interstitial inflammation stimulating iNOS to generate NO, in an attempt to mitigate the post-ischemic interactions between leukocytes and endothelium. ${ }^{36}$ Moreover, studies have shown that increased ROS production and iNOS expression lead to an overproduction of superoxide anion that induces cardiovascular alterations that contribute to hypertension. ${ }^{37}$ Thus, the beneficial or adverse effects of iNOS in hypertension can depend on the organ and the model studied.

The nNOS is expressed primarily in the macula densa and participates in the control of glomerular hemodynamics via tubuloglomerular feedback and renin release. ${ }^{33}$ Thus, nNOS protein levels have been reported to correlate inversely with developing kidney damage. ${ }^{38}$ In the renal cortex, nNOS mediates the synthesis of renin, dilates the afferent arterioles and reduces the reabsorption of sodium. ${ }^{32}$ Our data demonstrate a decrease in the expression of nNOS in the non-clipped kidney of $2 \mathrm{~K} 1 \mathrm{C}$ rats, which is directly related to the pathophysiology of the hypertensive model, demonstrating hemodynamic changes in both kidneys.

L-ARG infusion in the kidneys is reported to stimulate intrarenal NO production by enhancing NOS activity in vivo. ${ }^{35}$ We found that exogenous administration of L-ARG for 21 days increased the expression of eNOS, nNOS and iNOS. Rusai et al. ${ }^{38}$ showed that, in kidneys that underwent ischemia, supplementation with L-ARG for 7 days increased the expression of mRNA for the three isoforms of NOS. Intrarenal NO production stimulated by L-ARG also increases renal sodium excretion by a direct tubular action and by regulating vascular tone in the pressure natriuretic response in the renal medulla. ${ }^{35}$ In contrast, $2 \mathrm{~K} 1 \mathrm{C}$ rats showed increased iNOS expression, but decreased eNOS and nNOS expression. Evidence has been accumulating that, in pathological states, iNOS may be overexpressed, and both eNOS and nNOS expression can be altered. ${ }^{35}$ Ischemia decreases L-ARG concentrations in the renal cortex and medulla, resulting in a decreased substrate supply for NO synthesis. This situation can be reversed by exogenous supplementation of L-ARG, ${ }^{38}$ as was also demonstrated in this study.

Our results demonstrate that sympathetic afferent activity from the kidney participates in the genesis of the hypertension induced in the two-kidney one-clip model. Oral administration of aliskiren and L-arginine normalizes the RSNA and SBP, suggesting that the Ang II and NO are involved in the enhanced sympathetic afferent reflex in renovascular-hypertensive rats. Combined drug treatment is more efficient than monotherapy, demonstrating that both the RAAS and NO contribute to the pathogenesis of hypertension, as shown by the fact that L-arginine alone is capable of reducing but not normalizing blood pressure levels in a renovascular hypertension model. This new treatment proposal could reduce blood pressure levels, in addition to 
improving renal and cardiac functions and sympathetic activity, and would protect target organs.

\section{CONFLICT OF INTEREST}

The authors declare no conflict of interest.

\section{ACKNOWLEDGEMENTS}

This research was supported by a CNPq research grant to R.V. Tiradentes, and a CAPES grant to C.H. Santuzzi. This study was funded by Fundação de Amparo a Pesquisa do Espirito Santo (FAPES-Brazil) and Conselho Nacional de Desenvolvimento Científico e Tecnológico (CNPq-Brazil).

1 Esler M. Sympathetic nervous system: contribution to human hypertension and related cardiovascular diseases. J Cardiovasc Pharmacol 1995; 26: S24-S28.

2 Esler M. The sympathetic system and hypertension. Am J Hypertens 2000; 13: $99 \mathrm{~S}-105 \mathrm{~S}$.

3 Johansson M, Elam M, Rundqvist B, Eisenhofer G, Herlitz H, Lambert G, Friberg P. Increased sympathetic nerve activity in renovascular hypertension. Circulation 1999; 99: 2537-2542.

4 Burke SL, Evans RG, Head GA. Effects of chronic sympatho-inhibition on reflex control of renal blood flow and plasma rennin activity in renovascular hypertension. $\mathrm{Br} J$ Pharmacol 2010; 159: 438-448.

5 Burke SL, Head GA. Cardiac and renal baroreflex control during stress in conscious renovascular hypertensive rabbits: effect of rilmenidine. J Hypertens 2009; 27: $132-141$

6 Katholi RE, Whitlow PL, Winternitz SR, Oparil S. Importance of the renal nerves in established two-kidney,one clip Goldblatt hypertension. Hypertension 1982; 4: 166-174.

7 Rossi NF, Maliszewska-Scislo M, Chen H, Black SM, Sharma S, Ravikov R, Augustynia RA. Neuronal nitric oxide synthase within paraventricular nucleus: blood pressure and baroreflex in two-kidney, one-clip hypertensive rats. Exp Physiol 2010; 95: 845-857.

8 McBryde FD, Guild SJ, Barrett CJ, Osborn JW, Malpas SC. Angiotensin II-based hypertension and the sympathetic nervous system: the role of dose and increased dietary salt in rabbits. Exp Physiol 2007; 92: 831-840.

9 Ishimitsu T, Numabe A, Masuda T, Akabane T, Okamura A, Minami J, Matsuoka H. Angiotensin-II receptor antagonist combined with calcium channel blocker or diuretic for essential hypertension. Hypertens Res 2009; 32: 962-968.

10 Chen AD, Zhang SJ, Yuan N, Xu Y, De W, Gao XY, Zhu GQ. Angiotensin AT1 receptors in paraventricular nucleus contribute to sympathetic activation and enhanced cardiac sympathetic afferent reflex in renovascular hypertensive rats. Exp Physiol 2010; 96 : 94-103.

11 Zhu GQ, Xu Y, Zhou LM, Li YH, Fan LM, Wang W, Gao XY, Chen Q. Enhanced cardiac sympathetic afferent reflex involved in sympathetic overactivity in renovascular hypertensive rats. Exp Physiol 2009; 94: 785-794.

12 Nishikawa T, Omura M, Saito J, Matsuzawa Y. The possibility of resistant hypertension during the treatment of hypertensive patients. Hypertens Res 2013; 36: 924-929.

13 Nussberger J, Wuerzner G, Jensen C, Brunner HR. Angiotensin II suppression in humans by the orally active renin inhibitor Aliskiren (SPP100): comparison with enalapril. Hypertension 2002; 39: E1-E8.

14 Chen Y, Meng L, Shao H, Yu F. Aliskiren vs other antihypertensive drugs in the treatment of hypertension: a meta-analysis. Hypertens Res 2013; 36: 252-261.

15 Chou CL, Pang CY, Lee TJ, Fang TC. Direct renin inhibitor prevents and ameliorates insulin resistance, aortic endothelial dysfunction and vascular remodeling in fructosefed hypertensive rats. Hypertens Res 2013; 36: 123-128.

16 Gouvêa SA, Moysés MR, Bissoli NS, Pires JGP, Cabral AM, Abreu GR. Oral administration of L-arginine decreases blood pressure and increases renal excretion of sodium and water in renovascular hypertensive rats. Braz J Med Biol Res 2002; 7: 943-949.

17 Gouvea SA, Bissoli NS, Moysés MR, Cicilini MA, Pires JGP, Abreu GR. Activity of angiotensin-converting enzyme after treatment with $\mathrm{L}$-arginine in renovascular hypertension. Clin Exp Hypertens 2004; 56: 569-579.
18 Graceli JB, Cicilini MA, Bissoli NS, Abreu GR, Moysés MR. Roles of estrogen and progesterone in modulating renal nerve function in the rat kidney. Braz J Med Biol Res 2013; 46: 521-527.

19 Liu JL, Murakami H, Sanderford M, Bishop VS, Zucker IH. ANG II and baroreflex function in rabbits with CHF and lesions of the area postrema. Am J Physiol Heart Circ Physiol 1999; 277: H342-H350.

20 Lowry OH, Rosbrough NJ, Farr AL, Randall RJ. Protein measurement with the Folin phenol reagent. J Biol Chem 1951; 193: 265-275.

21 Martins-Oliveira A, Castro MM, Oliveira DMM, Rizzi E, Ceron CS, Guimaraes D, Reis RI, Costa-Neto CM, Casarini DE, Ribeiro AA, Gerlach RF, Tanus-Santos JE. Contrasting effects of aliskiren versus losartan on hypertensive vascular remodeling. Int J Cardiol 2013; 167: 1199-1205.

22 Yoshitomi Y, Tarutani Y, Tsujibayashi T, Yamaguchi A, Ishii T, Kaneki M, Kawanishi K, Minai K, Saitou Y, Sakurai S, Suwa S. Effectiveness of the direct renin inhibitor, aliskiren, in patients with resistant hypertension. Int Heart J 2013; 54: 88-92.

23 Sigmon DH, Beierwaltes WH. Influence of nitric oxide in the chronic Phase of Two-Kidney, One Clip Renovascular Hypertension. Hypertension 1998; 31: 649-656.

24 Kishi T. Regulation of the sympathetic nervous system by nitric oxide and oxidative stress in the rostral ventrolateral medulla: 2012 Academic Conference Award from the Japanese Society of Hypertension. Hypertens Res 2013; 36: 845-851.

25 Xu B, Chen WW, Fan ZD, Han Y, Xiong XQ, Gao XY, Zhu GQ. Responses of neurons in paraventricular nucleus to activation of cardiac afferents and acute myocardial ischemia in rats. Exp Physiol 2011; 96: 295-304.

26 Zhong MK, Duan YC, Chen AD, Xu B, Gao XY, De W, Zhu GQ. Paraventricular nucleus is involved in the central pathway of cardiac sympathetic afferent reflex in rats. Exp Physiol 2008; 93: 746-753.

27 Helle F, Hultström M, Skogstrand T, Palm F, Iversen BM. Angiotensin II-induced contraction is attenuated by nitric oxide in afferent arterioles from the nonclipped kidney in 2K1C. Am J Physiol Renal Physiol 2009; 296: F78-F86.

28 Prieto MC, González-Villalobos RA, Botros FT, Martin VL, Pagán J, Satou R, Lara LS, Feng $Y$, Fernandes FB, Kobori H, Casarini DE, Navar LG. Reciprocal changes in renal ACE/ANG II and ACE2/ANG 1-7 are associated with enhanced collecting duct renin in Goldblatt hypertensive rats. Am J Physiol Renal Physiol 2011; 300: F749-F755.

29 Rizzi E, Castro MM, Ceron CS, Neto-Neves EM, Prado CM, Rossi MA, Tanus-Santos JE, Gerlach RF. Tempol inhibits TGF- $\beta$ and MMPs upregulation and prevents cardiac hypertensive changes. Int J Cardiol 2013; 165: 165-173.

30 Schefe JH, Neumann C, Goebel M, Danser J, Kirsch S, Gust R, Kintscher U, Unger T, Funke-Kaiser H. Prorenin engages the (pro)rennin receptor like rennin and both ligand activities are unopposed by aliskiren. J Hypertens 2008; 26: 1787-1794.

31 Whaley-Connell A, Habibi J, Nistala R, Hayden MR, Pulakat L, Sinak C, Locher B, Ferrario CM, Sowers JR. Combination of direct renin inhibition with angiotensin type 1 receptor blockade improves aldosterone but does not improve kidney injury in the transgenic Ren2 rat. Regul Peptides 2012; 176: 36-44.

32 Tain YL, Hsu CN, Lin CY, Huang LT, Lau YT. Aliskiren prevents hypertension and reduces asymmetric dimethylarginine in young spontaneously hypertensive rats. Eur $\mathrm{J}$ Pharmacol 2011; 670: 561-565.

33 Cherla G, Jaimes EA. Role of L-Arginine in the pathogenesis and treatment of renal disease. J Nutr 2004; 134: 2801 S-2806 S.

34 Wickman A, Andersson IJ, Jia J, Bergströn G. Endothelial nitric oxide synthase protein is reduced in the renal medulla of two-kidney, one-clip hypertensive rats. J Hypertens 2001; 19: 1665-1673.

35 Huang HS, Ma MC, Chen J. Chronic I-arginine administration increases oxidative and nitrosative stress in rat hyperoxaluric kidneys and excessive crystal deposition. Am J Physiol Renal Physiol 2008; 295: F388-F396.

36 Park KM, Byun JY, Kramers C, Kim JI, Huang PL, Bonventre JV. Inducible nitric-oxide synthase is an important contributor to prolonged protective effects of ischemic preconditioning in the mouse kidney. J Biol Chem 2003; 278: 27256-27266.

37 Cau SBA, Guimaraes DA, Rizzi E, Ceron CS, Souza LL, Tirapelli CR, Gerlach RF, Tanus-Santos JE. Pyrrolidine dithiocarbamate down-regulates vascular matrix metalloproteinases and ameliorates vascular dysfunction and remodelling in renovascular hypertension. Br J Pharmacol 2011; 164: 372-381.

38 Rusai K, Fekete A, Szebeni B, Vannay A, Bokodi G, Müller V, Viklicky O, Bloudickova S, Rajnoch J, Heemann U, Reusz G, Szabó A, Tulassay T, Szabó AJ. Effect of inhibition of neuronal nitric oxide synthase and $\mathrm{L}$-arginine supplementation on renal ischaemiareperfusion injury and the renal nitric oxide system. Clin Exp Pharmacol Physiol 2008; 35: 1183-1189. 